\title{
GEOMETRIA DESCRITIVA E DEFICIÊNCIA VISUAL - ACESSIBILIDADE POR MEIO DE MATERIAIS ADAPTADOS
}

\section{DESCRIPTIVE GEOMETRY AND VISUAL IMPAIRMENT - ACCESSIBILITY THROUGH ADAPTED MATERIALS}

\author{
Eduardo José Lanes, M.Sc. \\ Colégio Pedro II \\ edlannes100@gmail.com
}

Palavras-chave: Representação espacial, deficiência visual, Colégio Pedro II.

\begin{abstract}
O paradigma da educação inclusiva deve ser sempre lembrado junto às práticas pedagógicas. Como forma de contribuir com a questão e fomentar outras produções, o presente artigo relata as etapas da pesquisa de Mestrado Profissional em Práticas de Educação Básica do Colégio Pedro II (Rio de Janeiro - RJ). Os trabalhos descrevem a produção, os testes e as avaliações do uso de três modelos de épuras táteis, de modo a possibilitar a compreensão dos conceitos iniciais da Geometria Descritiva. Esses protótipos foram apreciados e manipulados por um aluno cego congênito da referida instituição de ensino. Um guia de confecção e utilização dos protótipos e uma audioaula de Geometria Descritiva também compuseram o produto educacional. Basicamente, a avaliação do material adaptado foi realizada pelo respondente que, além de sugerir melhorias, classificou a experimentação como satisfatória.
\end{abstract}

Key-words: Space representation, visual impairment, Colégio Pedro II.

The paradigm of inclusive education must always be remembered alongside pedagogical practices. As a way of contributing to the question and fostering other productions, this paper relates the stages of the research of Professional Master's Degree in Practices of Basic Education of the Colégio Pedro II (Rio de Janeiro - RJ). The author describes the production, tests and evaluations of the use of three tactile models of the $2 D$ representation of points, in order to allow the understanding of the basic concepts of Descriptive Geometry. These prototypes were appreciated and manipulated by a born blind student of said educational institution. A guide for the making and use of prototypes and a descriptive geometry audio-cassette also made up the educational product. Basically, the evaluation of the adapted material was performed by the respondent who, besides suggesting improvements, classified the experimentation as satisfactory. 


\section{$16^{\circ}$ \\ ERGODESIGN USIHC CINAHPA}

\section{Introdução}

No decorrer da história das civilizações, encontram-se relatos (SILVA, 2010; SILVA, 1987) que mostram, mais do que preconceitos, atitudes de repulsa, segregação ou extermínio da pessoa portadora de deficiência. Em nome de uma sociedade perfeita, genocídios eram comuns, pois muitas civilizações acreditavam que a criança nascida com alguma deficiência era sinal da presença do demônio. Em outras, considerava-se como uma maldição por pecados de gerações anteriores; um castigo. A maioria das civilizações passou a repensar a questão da pessoa com deficiência. Essas reflexões suscitaram não somente melhorias da qualidade de vida social como também foram responsáveis pelas reformulações das leis que tratam o assunto.

Assim como as sociedades começam a se sensibilizar, também a escola passa a reconsiderar o seu papel na formação do indivíduo (LANES, 2016). Nessa perspectiva, as discussões sobre o paradigma da educação inclusiva ganham um espaço a mais neste trabalho. A inclusão é uma ação emergente e que necessita de um olhar diferenciado. (SÁNCHEZ, 2005).

Este artigo relata a pesquisa desenvolvida durante o curso de Mestrado Profissional em Práticas de Educação Básica do Colégio Pedro II (Rio de Janeiro - RJ). O estudo teve como propósito elaborar, testar e validar três soluções de épuras táteis de modo a permitir que alunos com deficiência visual pudessem compreender os preceitos da Geometria Descritiva. Na feição de um estudo de caso (YIN, 2011), contou-se com a participação de um aluno cego congênito protegido aqui pela abreviação de V. F. S. - do Campus São Cristóvão III da referida instituição de ensino, que cursava, no ano de 2016 , a $2^{\mathrm{a}}$ série do Ensino Médio. Além da dissertação e das épuras táteis, um guia de confecção e utilização dos protótipos e uma audioaula de Geometria Descritiva também compuseram o produto educacional. $16^{\circ}$ Ergodesign - Congresso Internacional de Ergonomia e Usabilidade de Interfaces Humano Tecnológica: Produto, Informações Ambientes Construídos e Transporte

$16^{\circ}$ USIHC - Congresso Internacional de Ergonomia e Usabilidade de Interfaces Humano Computador

CINAHPA | 2017 - Congresso Internacional de Ambientes Hipermídia para Aprendizagem.
Para a base teórica, Vygotsky (1997) e Howard Gardner (1994) foram elencados, dadas as suas colaborações sobre "compensação" e "inteligências múltiplas", respectivamente. Também se consultaram diversas publicações, cujos eixos temáticos eram, de uma forma ou de outra, voltados para a deficiência visual. Neste texto, arrolam-se as dinâmicas de construção dos produtos educacionais; o desenvolvimento da pesquisa; a metodologia utilizada e os resultados seguidos de avaliações, que incluíram as sugestões do respondente sobre o produto educacional e a própria pesquisa.

Apesar de a Geometria Descritiva ser uma disciplina de caráter tecnicista, pretendeu-se com o trabalho destacar a importância e a emergência da inclusão escolar; uma questão de humanidade e solidariedade. Também foi preocupação do autor mostrar que, a despeito de o Desenho ser uma matéria de proposições imagéticas, a compreensão do espaço tridimensional pode ser decodificada por alunos cegos, ainda que de maneira tátil ou auditiva.

\section{Referencial Teórico}

Pelo fato de a pesquisa se desenvolver com a experimentação de materiais táteis, buscaram-se teóricos que trataram, de uma forma ou de outra, as dificuldades e as compensações que os alunos com DV precisam ter para alcançar o conhecimento. $\mathrm{Na}$ educação, é emergente e mais que justa a adequação - e criação - dos materiais didáticos que contemplem a acessibilidade pelo tato.

Quanto à problemática referente à defectologia, Vygotsky (1997) entende que o aluno cego, por exemplo, deve recorrer ao que chama de "compensação" para a compreensão do mundo, para o conhecimento e, na sequência, então, sentirse incluído (ou menos excluído). Quando há uma lacuna em razão de alguma deficiência, abrem-se "novas vias de acesso". Sobre essa consideração, mas ainda no mesmo sentido, o autor acrescenta:

"Mas seja qual for o resultado que se espera de

Realização:




\section{$16^{\circ}$ \\ ERGODESIGN USIHC CINAHPA}

um processo de compensação, sempre e em todas as circunstâncias o desenvolvimento agravado por uma deficiência constitui um processo (orgânico e psicológico) de criação e recriação da personalidade da criança, com base na reorganização de todas as funções de adaptação, da formação de novos processos superestruturados, substitutivos, niveladores, que são gerados pela deficiência, e da abertura de novas vias de acesso para o desenvolvimento." (VYGOSTKY, 1997, p. 16)

Aliadas à questão da "compensação" anunciada por Vygotsky (1997), as "inteligências múltiplas" tratadas por Howard Gardner (1994) compõem o interesse do presente trabalho. Na medida em que a pesquisa visa à produção de novos materiais táteis, encontra-se na obra deste último uma modalidade específica - a "inteligência espacial" - quando afirma que "a pessoa com DV forma um modelo mental do mundo tridimensional" (GARDNER, 1994, p. 15). É oportuno ressaltar que ambos os teóricos consideram importante o preenchimento da lacuna provocada por uma deficiência; seja pela "compensação", seja pelo uso de "múltiplas inteligências".

As novas soluções de materiais didáticos para alunos com DV ganham maior suporte e motivação por meio dos seguintes comentários de Gardner:

"As populações cegas ilustram a distinção entre a inteligência espacial e a percepção visual. Uma pessoa cega pode reconhecer formas através de um método indireto: passar a mão ao longo do objeto traduz a duração do movimento, que por sua vez é traduzida no formato do objeto. Para a pessoa cega, o sistema perceptivo da modalidade tátil equivale à modalidade visual na pessoa que enxerga." (GARDNER, 1994, p. 26)

A partir de diversas consultas, não foram localizados textos que tratassem especificamente de uma épura tátil. Entretanto, vale dar destaque a algumas produções que apresentam consonância com a proposta de uma educação inclusiva por meio de materiais adaptados para alunos com DV, como, por exemplo, os estudos de Leila Gross (2015), professora de Artes Visuais do Colégio $16^{\circ}$ Ergodesign - Congresso Internacional de Ergonomia e Usabilidade de Interfaces Humano Tecnológica: Produto, Informações Ambientes Construídos e Transporte

$16^{\circ}$ USIHC - Congresso Internacional de Ergonomia e Usabilidade de Interfaces Humano Computador

CINAHPA | 2017 - Congresso Internacional de Ambientes Hipermídia para Aprendizagem.

Pedro II (Rio de Janeiro-RJ), que marca colaboração relevante, pois sua pesquisa também se desenvolveu no mesmo locus e com clientela idêntica à eleita pelo autor deste artigo. Segue um registro de sua tese em que aponta a problematização de trabalho junto a alunos com DV:

"Tenho como hipótese que as questões que envolvem a presença da imagem na educação de cegos em situação inclusiva não se resolvem apenas com a confecção do material adaptado. Há necessidade de uma adaptação do professor e da turma quanto à apresentação do material durante a aula, já que há um descompasso no tempo de compreensão da imagem pelo aluno cego e pelos demais que enxergam [...]." (GROSS, 2015, p. 20)

Em meio às diversas releituras experimentadas por essa pesquisadora, com o objetivo de dar acessibilidade de portadores de DV às Artes Visuais, aquela que chamou de "interpretação tátil" de quadros emblemáticos da história da arte (figura 01) serve como exemplo ao produto aqui descrito, comparando-se uma épura tradicional com seu modelo tátil.



Figura 01: Interpretação Tátil - Monalisa

Fotocópia, tecidos, tinta relevo sobre papel cartão, 21x19,6x2cm. (GROSS, 2009)

Fonte: Gross, 2015, p. 10 


\section{$16^{\circ}$ \\ ERGODESIGN USIHC CINAHPA}

Para a presente pesquisa, além de Leila Gross, foram elencados, ao longo da revisão de literatura, outros professores do Colégio Pedro II e mais alguns de diferentes instituições. Também vale repetir que todos elegeram a deficiência visual como eixo para as suas produções/contribuições. Destacam-se, então: Leonardo Bueno (2013), pela manipulação de maquetes de sólidos dinâmicos; André Tato Santos (2009), pelo "equacionamento de material tátil" para o estudo de Física; Luciano P. Paixão (2012), pela confecção de uma Linha do Tempo Tátil no ensino de História e Ustane F. C. Oliveira (2014) pelos desenhos adaptados para alunos com DV.

\section{0 produto educacional}

Como exigência do Mestrado Profissional em Práticas de Educação Básica do Colégio Pedro II, os alunos deste curso, além da dissertação, devem elaborar um produto educacional relacionado ao tema de sua pesquisa. A épura tátil constitui o produto central. Entretanto, mais dois itens integram o conjunto: um guia de confecção e utilização do protótipo e uma audioaula de Geometria Descritiva. Considerada como uma geometria projetiva, essa disciplina estuda os elementos do espaço tridimensional por meio de projeções ortogonais registradas em planos, chamados planos de projeção. Gaspard Monge (1746 - 1818), matemático francês, sistematizou o estudo da GD que se conhece até hoje. De seu nome, origina-se a expressão "projeções mongeanas" quando se alude às projeções ortogonais de um objeto. Dos autores de livros sobre Geometria Descritiva, Virgílio Athayde Pinheiro (1961) figura como grande referência, principalmente entre professores de Desenho do CPII. Segundo este autor, "a Geometria Descritiva é o mais importante método de representação por projeções ortogonais, não só pela simplicidade de sua concepção, como também pela ampla variedade de aplicações a que se presta" (PINHEIRO, 1961, p. 8-9). Sobre as projeções mongeanas, o professor esclarece:

"Consiste o método mongeano em assegurar a univocidade da correspondência objeto-imagem, no sentido desta para aquele, por meio de uma $16^{\circ}$ Ergodesign - Congresso Internacional de Ergonomia e Usabilidade de Interfaces Humano Tecnológica: Produto, Informações Ambientes Construídos e Transporte

$16^{\circ}$ USIHC - Congresso Internacional de Ergonomia e Usabilidade de Interfaces Humano Computador

CINAHPA | 2017 - Congresso Internacional de Ambientes Hipermídia para Aprendizagem.

segunda projeção ortogonal. Para isso, consideremos dois planos de projeção $\left(\pi^{\prime}\right)$ e $(\pi)$, que suporemos perpendiculares." (PINHEIRO, 1961, p. 09)

A figura 02 sintetiza a dinâmica de projeções de um ponto do espaço tridimensional em dois planos de projeção. Após o rebatimento desses planos (um sobre o outro), define-se a situação bidimensional conhecida como épura.



Figura 02: Projeções do ponto

Fonte: o autor (2016)

\subsection{A construção dos protótipos}

Para os trabalhos com o sujeito da pesquisa, três modelos diferentes de épuras táteis foram apresentados, de modo a suscitar opiniões e sugestões por ocasião das entrevistas semiestruturadas. Dois desses protótipos possuem a mesma configuração: marcação das projeções do ponto por meio de alfinetes fincados em borracha. A diferença está nos materiais e no tamanho: o primeiro protótipo, com placas de madeira no formato A4; o segundo, com placas de acrílico no formato $\mathrm{A} 3$, portanto, maior. Na sequência (figuras 03, 04 e 05), estão ilustrados os três modelos utilizados. 


\section{$16^{\circ}$ \\ ERGODESIGN USIHC CINAHPA}



Figura 03: Primeiro modelo de épura tátil - formato A4 Materiais: madeira e alfinetes sobre borracha Fonte: o autor (2016).

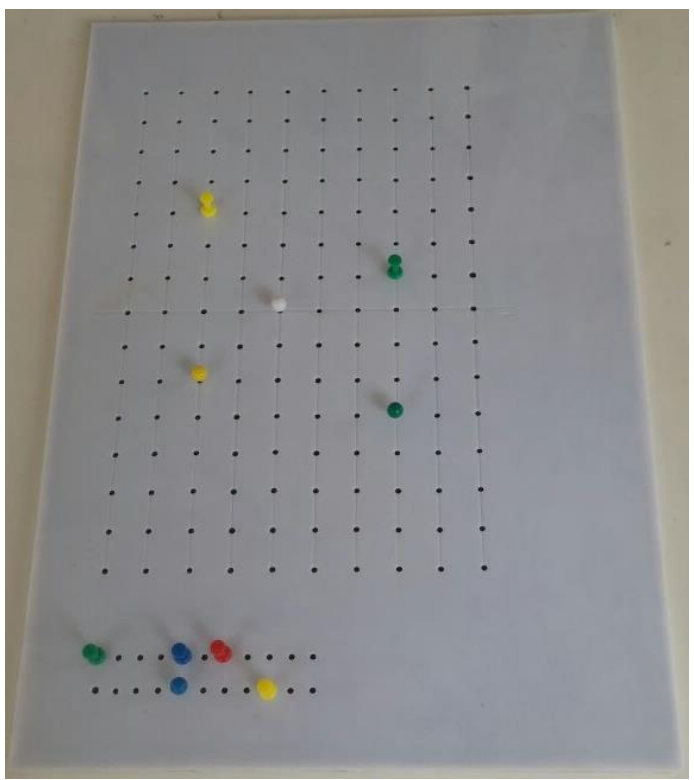

Figura 04: Segundo modelo - formato A3 Materiais: acrílico e alfinetes sobre borracha Fonte: o autor (2016). $16^{\circ}$ Ergodesign - Congresso Internacional de Ergonomia e Usabilidade de Interfaces Humano Tecnológica: Produto, Informações Ambientes Construídos e Transporte

$16^{\circ}$ USIHC - Congresso Internacional de Ergonomia e Usabilidade de Interfaces Humano Computador

CINAHPA | 2017 - Congresso Internacional de Ambientes Hipermídia para Aprendizagem.

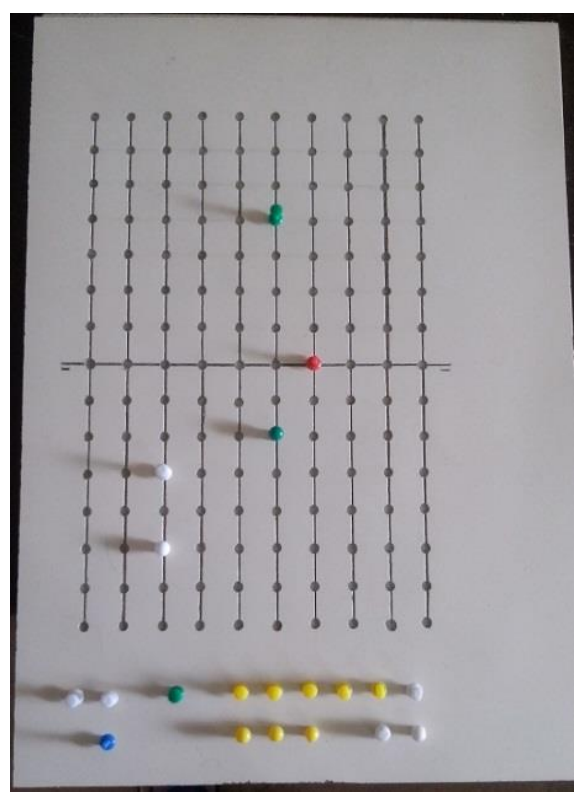

Figura 05: Terceiro modelo - formato A3

Materiais: compensado (fundo), fórmica (frente), metal e alfinetes com ímãs

Fonte: o autor (2016).

Exceto pelo corte da chapa de metal, todas as confecções foram realizadas pelo autor. Eleito pelo respondente, o terceiro modelo foi considerado o de melhor usabilidade. Por esta razão, vale apresentar o detalhe (figura 06) dessa épura tátil.

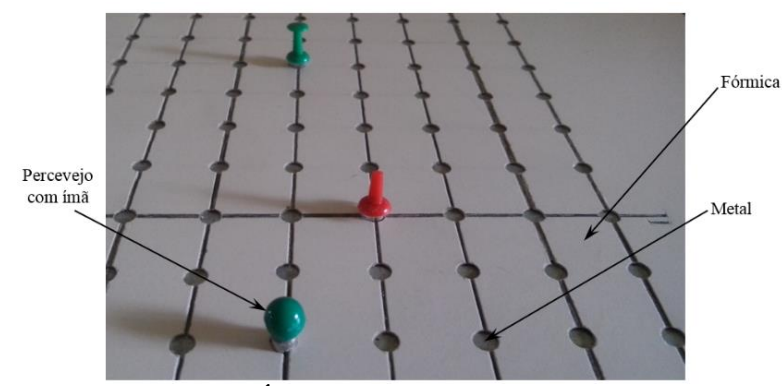

Figura 06 - Épura com metal e ímãs (detalhe) Fonte: o autor (2016).

Com os três modelos, criou-se uma convenção para os formatos das cabeças dos alfinetes/percevejos, de modo que cada uma representasse uma determinada projeção mongeana. Foi combinado, também, um formato específico para a origem das abscissas, ponto a partir do qual se marcam essas projeções na épura. A figura 07 mostra um dos critérios utilizados durante a pesquisa/aula com o aluno. 


\section{$16^{\circ}$ \\ ERGODESIGN USIHC CINAHPA}



Figura 07: Critérios para os formatos das cabeças dos alfinetes

Fonte: o autor (2016).

Escolher cores diferentes de hastes pode ser uma boa opção para facilitar o trabalho do professor mediador. Na possibilidade de haver mais de um ponto projetado na épura, aconselha-se desbastar/lixar as cabeças dos alfinetes, criando nova convenção de formatos. Veem-se, na figura 08, algumas soluções.

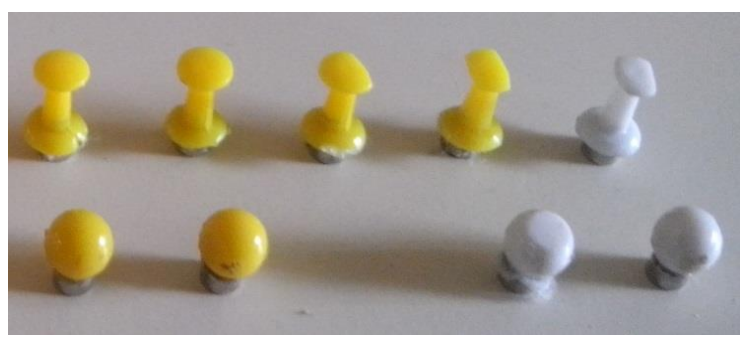

Figura 08: Soluções/critérios de formatos Fonte: o autor (2016).

\subsection{O guia de confecção e utilização do produto}

Disponibilizado em:

https://www.cp2.g12.br/blog/mpcp2/files/2017/03/ 2015_produtoeducacional_EDUARDOJOS\%C3\%89-LANES.pdf, este caderno foi organizado em três módulos, a saber:

\subsubsection{Módulo A - Sobre a confecção dos três} modelos de épuras táteis. Por meio de um passo a passo com textos e ilustrações, o docente interessado na confecção de materiais adaptados terá a oportunidade de encontrar algumas sugestões de trabalhos, mesmo não sendo professor de Desenho. As etapas descrevem a confecção dos modelos utilizados na pesquisa. Entretanto, as técnicas e materiais podem ser adequados para 0 uso específico de quaisquer outras iniciativas. $16^{\circ}$ Ergodesign - Congresso Internacional de Ergonomia e Usabilidade de Interfaces Humano Tecnológica: Produto, Informações Ambientes Construídos e Transporte

$16^{\circ}$ USIHC - Congresso Internacional de Ergonomia e Usabilidade de Interfaces Humano Computador

CINAHPA | 2017 - Congresso Internacional de Ambientes Hipermídia para Aprendizagem.

Recomendações de tipo de broca (diâmetro) para os furos nas placas são, por exemplo, descritas no texto, assim como alguns cuidados durante as construções.

3.2.2 Módulo B - Sobre os exercícios de projeções de pontos possibilitados por uma épura tátil. Um dos objetivos deste protótipo é a substituição da folha de papel (situação imagética) por outra superfície (madeira, acrílico ou fórmica) para compreensão tátil das projeções desses pontos. Neste módulo, então, a dinâmica de proposição de exercícios obedeceu à mesma utilizada para alunos videntes. Observar a apresentação gradual na complexidade das atividades também foi uma preocupação nessa etapa. Como estratégia didática, sugeriu-se, como enunciado do exercício, representar por suas projeções (alfinetes/percevejos) um ponto (A) a partir de suas coordenadas mongeanas $[\mathrm{x} ; \mathrm{y} ; \mathrm{z}]$. Em seguida, uma inversão: a partir de marcações feitas pelo professor mediador, informar as coordenadas respectivas. A localização de pontos também foi possibilitada neste módulo. $\mathrm{O}$ aluno deverá informar verbalmente a que diedro pertence o ponto proposto por suas projeções na épura tátil.

\subsubsection{Módulo C - Sobre a audioaula de}

Geometria Descritiva. Acrescentou-se, igualmente, o texto desse recurso didático no guia de confecção da épura tátil. Os detalhes desta subseção são descritos a seguir.

\subsection{A audioaula de Geometria Descritiva}

No primeiro dia de visita ao locus da pesquisa, o aluno com DV recebeu um kit de cinco CD's com a gravação da audioaula de Geometria Descritiva. A organização dos áudios foi feita em blocos, um em cada disco. Dessa forma, imaginava-se que seria mais eficiente para o aluno cego escolher qual $\mathrm{CD} /$ bloco gostaria de ouvir e em que momento. $\mathrm{O}$ texto serviu para auxiliar os estudos iniciais da Geometria Descritiva. Vale ressaltar que o propósito maior da pesquisa se restringe à representação do ponto. Por esta razão, os áudios deveriam informar e propor situações concretas de modo que um aluno com DV pudesse compreender, principalmente, o que são projeções, 


\section{$16^{\circ}$ \\ ERGODESIGN USIHC CINAHPA}

$16^{\circ}$ Ergodesign - Congresso Internacional de Ergonomia e Usabilidade de Interfaces Humano Tecnológica: Produto, Informações Ambientes Construídos e Transporte

$16^{\circ}$ USIHC - Congresso Internacional de Ergonomia e Usabilidade de Interfaces Humano Computador

CINAHPA | 2017 - Congresso Internacional de Ambientes Hipermídia para Aprendizagem. um conceito fundamental do método descritivo. $\mathrm{Na}$ elaboração do texto, houve uma preocupação em utilizar uma linguagem que se assemelhasse ao máximo a de uma aula, diferente da empregada num material puramente escrito. Com efeito, existem, ali, repetições de termos, retomadas de mesmo assunto, pausas e discussões intercaladas aos conteúdos.

Além do objetivo de otimizar a manipulação dos CD's, fez-se a divisão em blocos de maneira a desenvolver as etapas de estudo da GD gradual e cumulativamente, dada a própria dinâmica que a disciplina exige. A tabela 01 mostra a relação da divisão desses blocos, com a duração de cada um deles.

\begin{tabular}{|c|c|c|}
\hline Bloco & Descrição & Duração \\
\hline $\mathbf{0 1}$ & $\begin{array}{c}\text { Apresentação da pesquisa. Esta etapa } \\
\text { explica, de forma sucinta, por exemplo, } \\
\text { o que é uma épura. }\end{array}$ & 13min21s \\
\hline $\mathbf{0 2}$ & $\begin{array}{c}\text { Conhecendo a Geometria Descritiva } \\
\text { (primeira parte): Noç̃̃es de projeção, } \\
\text { planos de projeção, diedros e } \\
\text { coordenadas do ponto. }\end{array}$ & $\mathbf{9 m i n 2 9 s}$ \\
\hline $\mathbf{0 3}$ & $\begin{array}{c}\text { Conhecendo a Geometria Descritiva } \\
\text { (segunda parte): Projeções do ponto } \\
\text { nos diedros. }\end{array}$ & $\mathbf{2 2 m i n 3 8 s}$ \\
\hline $\mathbf{0 4}$ & $\begin{array}{c}\text { Conhecendo a Geometria Descritiva } \\
\text { (terceira parte): Projeções do ponto } \\
\text { nos semiplanos de projeção. }\end{array}$ & $\mathbf{1 2 m i n 3 1 s}$ \\
\hline & $\begin{array}{c}\text { Exemplos de exercícios utilizando a } \\
\text { épura tátil. }\end{array}$ & $\mathbf{1 6 m i n 3 2 s}$ \\
\hline
\end{tabular}

Tabela 01: Divisão dos blocos (audioaula) Fonte: o autor (2016).

\section{A pesquisa}

Essencialmente, a pesquisa procurou ratificar que, a despeito da DV, um indivíduo cego congênito consegue elaborar construções mentais de interpretação do mundo concreto à sua volta. Constituiu-se, portanto, como um estudo de caso único pois, segundo Yin (2001), “... no geral, o projeto de caso único é eminentemente justificável sob certas condições - nas quais o caso representa um teste crucial da teoria existente, nas quais o caso é um evento raro ou exclusivo ou nas quais o caso serve a um propósito revelador." (YIN, 2011, p. 67)
De maneira equivalente, segundo Gil (2010), "podem ser identificadas diferentes modalidades de estudos de caso único...", entre eles, "caso decisivo, utilizado quando se deseja confirmar, contestar ou estender uma teoria..." (GIL, 2010, p. 118).

A técnica de pesquisa também se deu por observação participante, conforme esclarece o mesmo autor: "A observação participante consiste na participação real do pesquisador na vida da comunidade [...] em que é realizada a pesquisa. $\mathrm{O}$ observador assume, pelo menos até certo ponto, o papel de membro do grupo." (Idem, p. 121). O autor da pesquisa foi mediador das experimentações, visto que a manipulação da épura tátil necessitava não só de explicações sobre a GD como também a mão do aluno cego deveria ser guiada pela do professor/autor, sobretudo nas primeiras investidas.

\subsection{Desenvolvimento}

As etapas da metodologia de trabalho deveriam prever: a) confecção das épuras táteis com seus diversos tamanhos e materiais; b) organização de um passo a passo da construção com ilustrações; c) disponibilização de maquetes construídas especialmente para os estudos com o aluno V. F. S.; d) apresentação dos modelos de épuras para os primeiros testes; e) acompanhamento dos trabalhos por observação participante; f) registros dos testes das soluções dos protótipos pelo respondente a partir de entrevistas semiestruturadas; e) compilação dos dados e avaliação das três soluções de épuras táteis e da própria pesquisa.

Antes dos trabalhos no locus da pesquisa, o autor construiu algumas maquetes especialmente para o estudante pesquisado ou quaisquer outros alunos (com ou sem DV) que desejassem experimentá-las. A informação tátil de uma linha de chamada, por exemplo, constitui um dos fatores fundamentais para a compreensão da GD por alunos com esse tipo de deficiência. As figuras 09 e 10 mostram essas maquetes antes e depois do rebatimento (dobra) dos planos de projeção.
Realização:

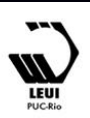




\section{$16^{\circ}$ \\ ERGODESIGN USIHC CINAHPA}

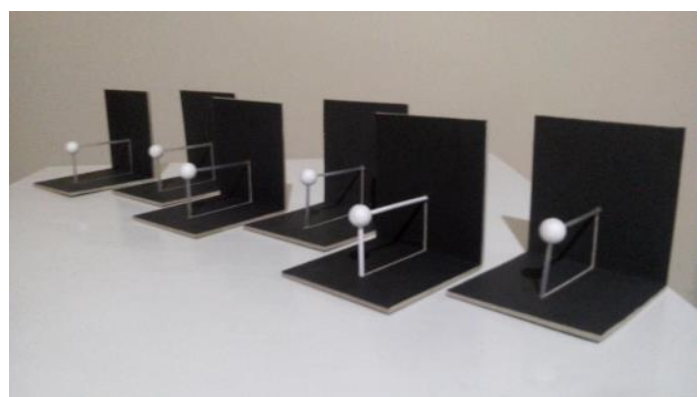

Figura 09: Maquetes especiais para a pesquisa (3D) Fonte: o autor (2016).



Figura 10: Maquete após rebatimento/dobra (2D) Fonte: o autor (2016).

Já no primeiro encontro no campus (figura 11), a épura tátil foi apresentada ao aluno. A ordem natural dos estudos com a GD deveria supor, primeiramente, a experimentação de maquetes especiais, como se costuma proceder nas aulas regulares para alunos videntes. Este adiantamento se deu pela própria apresentação da pesquisa e de seu autor. O protótipo lhe foi apresentado no primeiro encontro, em virtude de tratar-se da materialização do tema. Em seguida, trabalhou-se a noção de "projeção" por meio de explicações semelhantes às encontradas no texto da audioaula, como, por exemplo, utilizar partes do próprio corpo para simbolizar alguns elementos da Geometria Descritiva. $16^{\circ}$ Ergodesign - Congresso Internacional de Ergonomia e Usabilidade de Interfaces Humano Tecnológica: Produto, Informações Ambientes Construídos e Transporte

$16^{\circ}$ USIHC - Congresso Internacional de Ergonomia e Usabilidade de Interfaces Humano Computador

CINAHPA | 2017 - Congresso Internacional de Ambientes Hipermídia para Aprendizagem.

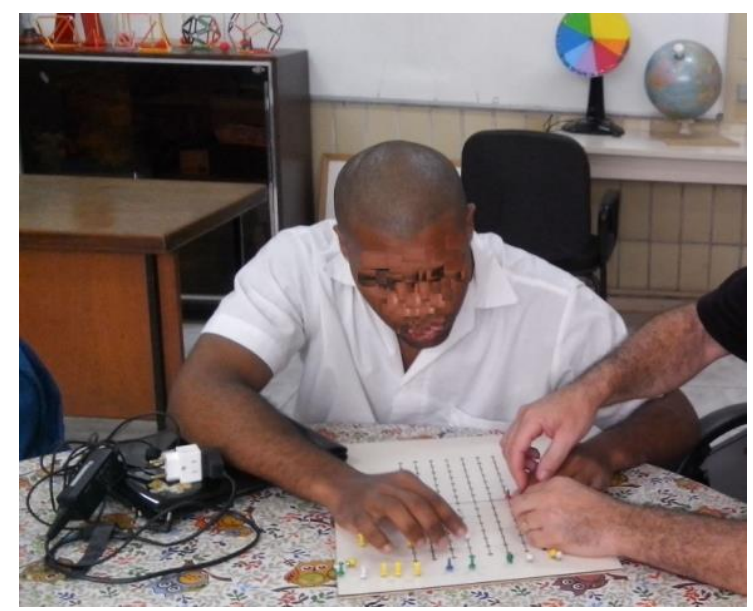

Figura 11: Primeira experimentação da épura tátil Fonte: o autor (2016).

Na sequência, buscou-se mostrar a mesma noção de projeção utilizando as maquetes dos planos de projeção. É imprescindível que esta noção seja de fato entendida para os efeitos dos estudos com a GD. Gradualmente, os termos típicos dessa disciplina são apresentados: elemento objetivo, projetantes, planos de projeção e projeção. Sempre que possível, as explicações dos conteúdos, tratadas com as maquetes, eram trazidas para a épura tátil, localizando aqueles termos específicos.

O último item da entrevista questionou o processo de formulação de uma imagem mental, consideração relevante para o trabalho. Segundo V. F. S., mesmo na condição de cego congênito, ele constrói em sua mente a figuração dos objetos concretos. "Mapa mental" é uma expressão que já pertence ao seu vocabulário cotidiano, trabalhada a partir de sua escola anterior, o Instituto Benjamin Constant (RJ). Com a Matemática, por exemplo, o aluno recebia materiais apropriados para a compreensão dos elementos da Geometria, mesmo sendo esta uma geometria plana. Uma vez matriculado no CPII, qualquer aluno do Ensino Médio com DV que deseja conhecer a GD precisará de atendimentos especiais e recursos didáticos adaptados, principalmente os que possuem cegueira total ou baixa visão severa. $\mathrm{O}$ produto educacional proposto nesta pesquisa se apresenta como sugestão para minimizar tal carência.
Realização:
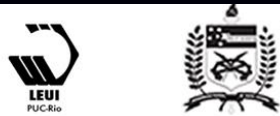


\section{$16^{\circ}$ \\ ERGODESIGN USIHC CINAHPA}

$16^{\circ}$ Ergodesign - Congresso Internacional de Ergonomia e Usabilidade de Interfaces Humano Tecnológica: Produto, Informações Ambientes Construídos e Transporte

$16^{\circ}$ USIHC - Congresso Internacional de Ergonomia e Usabilidade de Interfaces Humano Computador

CINAHPA | 2017 - Congresso Internacional de Ambientes Hipermídia para Aprendizagem.

\subsection{Análise e Resultados}

Para a análise e coleta de dados, a pesquisa considerou as observações de Gil (2010) e Bardin (2006). A partir de entrevista semiestruturada, o respondente considerou como válida a experimentação de uma épura tátil, além de informar que a pesquisa lhe proporcionou mais uma inclusão escolar. Optou-se por gravar as respostas em áudios, transcritos para a dissertação. A entrevista também previu espaços para as sugestões do aluno com relação a críticas e melhorias do protótipo. Relacionadas em quadros (um para cada categoria de perguntas), as respostas de V. F. S. constituíram o resumo da avaliação da pesquisa.

Este tipo de procedimento permite uma visão sintética dessas respostas. Sobre a importância de registros com esse aspecto, Costa (2010) informa que "A ciência procura entender e explicar fenômenos naturais complexos. A realidade em que tais fenômenos se fazem presentes é reconstruída através de modelos simplificados que podem ser expressos através de representações." (COSTA, 2010, p. 12)

Dos quatro quadros descritos na dissertação, vale o registro de um deles por apresentar uma espécie de resumo da experimentação do produto.

\begin{tabular}{l|l|r} 
2.a) & Dúvidas com a GD & $\begin{array}{r}\text { Valores das } \\
\text { coordenadas e } \\
\text { localização nos } \\
\text { diedros }\end{array}$ \\
\hline 2.b) & Contribuição da audioaula de GD & Muito \\
\hline 2.c) & Melhor tamanho para & A3 \\
\hline manipulação & Melhor modelo pela usabilidade & Metal com ímãs \\
\hline 2.e) & Esforço com a marcação de & Não \\
\hline alfinetes & $\begin{array}{l}\text { Maior sensibilidade das linhas de } \\
\text { chamada }\end{array}$ & Ambos os modelos \\
\hline 2.g) & Melhor solução (termos gerais) & Metal com ímãs
\end{tabular}

Quadro 01: Sobre a pesquisa e a manipulação da épura tátil.

Fonte: o autor (2016).

A partir da análise dos depoimentos do respondente, a pesquisa se apresentou como mais uma forma de inclusão pela intermediação de materiais adaptados. Entre poucas disciplinas que não oferecem atendimento no NAPNE (Núcleo de Atendimento às Pessoas com Necessidades Específicas - CPII), o Desenho, por este trabalho, pode ter uma mudança favorável.

Não se espera que a pesquisa se encerre nela mesma, mas, sim, que possa extrapolar o universo da GD e alcançar outras áreas do conhecimento. Também se deseja que os estudos sirvam como estímulo a novas produções de suportes didáticos com essa natureza para todas e quaisquer matérias.

\section{Considerações conclusivas}

As leis e discussões acerca do tratamento com a pessoa portadora de deficiência são relativamente recentes. Ousa-se supor que são recentes justamente pelo fato de que essas pessoas sequer podiam sair de suas casas; a própria família já lhes
Realização:

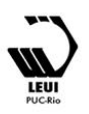




\section{$16^{\circ}$ \\ ERGODESIGN USIHC CINAHPA}

$16^{\circ}$ Ergodesign - Congresso Internacional de Ergonomia e Usabilidade de Interfaces Humano Tecnológica: Produto, Informações Ambientes Construídos e Transporte

$16^{\circ}$ USIHC - Congresso Internacional de Ergonomia e Usabilidade de Interfaces Humano Computador

CINAHPA | 2017 - Congresso Internacional de Ambientes Hipermídia para Aprendizagem. impunha o preconceito. Não é difícil imaginar que esse sentimento ainda perdure em muitas situações ou em algumas sociedades. Certamente, o conhecimento, a pesquisa e a tolerância são fundamentais para colaborar com a inclusão, seja escolar ou social. É importante mostrar que materiais adaptados servem para aproximar alunos com deficiência às diversas áreas do conhecimento. Tão relevante quanto poder ratificar essa proposição, este trabalho também se constitui como um apelo a novas investidas. As práticas pedagógicas com essa natureza estão mais ligadas à inquietude docente que às questões financeiras. Em todo o texto, houve a preocupação de não se utilizar a expressão "alunos deficientes visuais" e, sim, "com" esse impedimento, pois implicaria o ser da pessoa. De qualquer forma, a deficiência existe e é uma barreira que pode (e deve) ser quebrada pela escola se essa instituição possibilita aos professores as ações específicas e necessárias para a demanda em pauta já tão emergente.

Os testes da épura tátil com o aluno V. F. S. foram considerados satisfatórios dada a compreensão possibilitada pela intermediação deste material adaptado. A afirmação do sucesso dos trabalhos é entendida, fundamentalmente, a partir das avaliações do próprio respondente. É sempre válido repetir que o impedimento à compreensão do espaço não é uma questão ótica. "Enxergar" bem não significa ver bem, do ponto de vista oftalmológico; assim como "ouvir" bem não significa escutar bem, do ponto de vista fonoaudiológico. Percepção é, então, uma ideia muito mais completa e que, portanto, precisa ser desenvolvida/estimulada em todos os processos de ensino e aprendizagem para alunos normovisuais ou não.

Com esta proposta de trabalho - somada a tantas outras produções acadêmicas direcionadas à inclusão escolar -, espera-se que o espaço da educação básica, apesar de alguns dissabores, continue sendo palco de novas ideias, com práticas e discursos sempre motivadores.

\section{Bibliografia}

BARDIN, L. (2006). Análise de conteúdo (L. de
A. Rego \& A. Pinheiro, Trads.). Lisboa: Edições 70. (Obra original publicada em 1977).

BUENO, Leonardo C. Sólidos dinâmicos e o desenvolvimento da concepção espacial - $o$ caso da disciplina de Geometria Descritiva no curso de Arquitetura e Urbanismo da Faculdade de Arquitetura e Urbanismo da UFRJ - Dissertação (Mestrado) - Universidade Federal do Rio de Janeiro - Rio de Janeiro: UFRJ/FAU, 2013.

COSTA, Antônio Marcos V. A interpretação de gráficos em movimento. 2010, 160f. Brasília, DF. (Mestrado) Faculdade de Educação - Universidade Federal de Minas Gerais, 2010.

GARDNER, H. Estruturas da Mente - A teoria das inteligências múltiplas. $1^{a}$ ed., Porto Alegre: Artes Médicas, 1994.

GIL, Antonio Carlos. Como elaborar projetos de pesquisa. 5. ed. - São Paulo: Atlas, 2010.

GROSS, Leila. Arte e Inclusão: o Ensino da Arte na inclusão de alunos com deficiência visual no Colégio Pedro II. Rio de Janeiro, 2015. Tese (doutorado) - Universidade Federal do Rio de Janeiro, Faculdade de Educação, Programa de PósGraduação em Educação, 2015.

LANES, Eduardo J. Épura tátil - materiais adaptados aproximando alunos com deficiência visual à Geometria Descritiva. Dissertação (Mestrado). Colégio Pedro II - Rio de Janeiro, RJ. 2016.

OLIVEIRA, Ustane F. C. de. Representação gráfica para a pessoa com deficiência visual: limites e possibilidades de aprendizagem por meio do desenho. Dissertação (Mestrado). Feira de Santana, BA. 2014.

PAIXÃO, Luciano de Pontes. O uso de recursos didáticos no ensino de História para deficientes visuais. Revista Benjamin Constant, n. 50, 2012. Disponível em:

http://www.ibc.gov.br/revistabenjaminconstant/ind ex.php/b3njc0nst/article/viewFile/9/21. Acesso: set. 2016.
Realização:

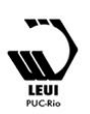




\section{$16^{\circ}$ \\ ERGODESIGN USIHC CINAHPA}

$16^{\circ}$ Ergodesign - Congresso Internacional de Ergonomia e Usabilidade de Interfaces Humano Tecnológica: Produto, Informações Ambientes Construídos e Transporte

$16^{\circ}$ USIHC - Congresso Internacional de Ergonomia e Usabilidade de Interfaces Humano Computador

CINAHPA | 2017 - Congresso Internacional de Ambientes Hipermídia para Aprendizagem.

PINHEIRO, Virgílio A. Noções de geometria descritiva: ponto - reta - plano. Rio de Janeiro: Ao Livro Técnico, 1961.

SANTOS, André L. T. L. Material de equacionamento tátil para usuários do sistema braille. Dissertação (Mestrado). CEFET/RJ, RJ, 2009.

SILVA, Aline Maira da. Educação especial e inclusão escolar: história e fundamentos. Curitiba: Ibpex, 2010.

SILVA, Otto Marques da. A Epopeia Ignorada A Pessoa Deficiente na História do Mundo de Ontem e de Hoje. São Paulo: CEDAS, 1987.

VYGOTSKY, Lev S. Obras Escogidas V Fundamentos de defectología. Madrid: Visor Dis., 1997.

YIN, Robert K. Estudo de caso: planejamento e métodos. Trad. Daniel Grassi. $2^{\mathrm{a}}$ ed. Porto Alegre: Bookman, 2001 